\title{
David P. Green, Robert N. Hotschkiss, William C. Pederson, Scott W. Wolfe (eds) (2005): Green's operative hand surgery, 5th edn
}

\author{
Elsevier Churchill Livingstone, 2 Vol, 2313 pp., num. figs., 425.00 €, ISBN 0-443-06626-4
}

Pierre H. Kehr · Philippe Liverneaux

Received: 11 June 2009 / Accepted: 30 June 2009 / Published online: 30 July 2009

(C) Springer-Verlag 2009

The Green is the uncontested reference book of several surgeons' generations of the hand, the resident to the professor of university. Fifth edition is enriched by the contribution of a new team of international editors, selected carefully according to their domains of excellence.

It is an inexhaustible source of data on techniques in open surgery as under arthroscopy. For every subject, operating techniques the most common are exposed, before the author delivers us tricks and craftiness of his favorite technique.
A very useful CD-ROM sends back to the summaries of main references quoted in the work. One regrets simply not to be able to have an electronic version of the Green, because the weight of two volumes prevents the transport of it.

Conflict of interest statement No funds were received in support of this study. 